\title{
The work behaviors of patients with allergic rhinitis (AR) during the autumn pollen season
}

\author{
Lin $\mathrm{Xi}^{1,2,3,4}$, Guangxi Wang ${ }^{1,2}$, Bowen Shi ${ }^{1,2}$, Yongjuan $\mathrm{Li}^{1,2}$, Luo Zhang ${ }^{3,4}$ \\ ${ }^{1}$ CAS Key Laboratory of Behavioral Science, Institute of Psychology, Chinese Academy of Sciences, Beijing, China; ${ }^{2}$ Department of Psychology, \\ University of Chinese Academy of Sciences, Beijing, China; ${ }^{3}$ Department of Otolaryngology, Head and Neck Surgery, Beijing Tongren Hospital, \\ Capital Medical University, Beijing, China; ${ }^{4}$ Beijing Key Laboratory of Nasal Diseases, Beijing Institute of Otolaryngology, Beijing, China \\ Contributions: (I) Conception and design: L Xi, Y Li; (II) Administrative support: Y Li, L Zhang; (III) Provision of study materials or patients: None; \\ (IV) Collection and assembly of data: L Xi, G Wang, B Shi; (V) Data analysis and interpretation: L Xi, G Wang; (VI) Manuscript writing: All authors; \\ (VII) Final approval of manuscript: All authors. \\ Correspondence to: Yongjuan Li, PhD. Institute of Psychology, Chinese Academy of Sciences, No. 16 Lincui road, Chaoyang District, Beijing 100101, \\ China. Email: liyj@psych.ac.cn; Luo Zhang, MD, PhD. Beijing Tongren Hospital, Capital Medical University, Beijing Institute of Otolaryngology, \\ No. 17 Hougou Hutong, Dongcheng District, Beijing 100005, China. Email: drzhangl39@163.com.
}

\begin{abstract}
Background: This study aims to analyze the work behaviors of patients with allergic rhinitis (AR) during the autumn pollen season, using a 2-week diary survey.

Methods: In this study, we recruited patients with seasonal allergic rhinitis (SAR) who were allergic to autumn pollen using an experience sampling method. All participants completed a 2-week survey using the WeChat app during the autumn pollen season (September 16, 2018 through to September 30, 2018). Collected data included participants' general characteristics, nasal symptoms, symptoms of insomnia, mood, and unethical work behaviors.

Results: The results showed that pollen concentration had a significant positive effect on the symptoms of rhinitis $(\mathrm{P}<0.001)$. Nasal symptoms had direct, positive effects on night-time insomnia $(\mathrm{P}<0.01)$ and a negative mood the next day $(\mathrm{P}<0.05)$. Insomnia positively affected a negative mood the next day $(\mathrm{P}<0.01)$, while negative mood exhibited a direct, positive effect on unethical work behaviors $(\mathrm{P}<0.05)$. Furthermore, pollen concentration, nasal symptoms, and insomnia were indirectly but positively associated with unethical work behaviors in patients with SAR.

Conclusions: Nasal symptoms in patients with SAR were aggravated by pollen dispersion that induced a higher incidence of insomnia, which subsequently provoked a negative mood the next day. Therefore, the spillover effects of seasonal pollen included an increased incidence of unethical work behaviors.
\end{abstract}

Keywords: Allergic rhinitis; nasal symptoms; insomnia; negative mood; unethical work behavior

Submitted Jan 20, 2020. Accepted for publication Jul 13, 2020.

doi: $10.21037 /$ apm-20-267

View this article at: http://dx.doi.org/10.21037/apm-20-267

\section{Introduction}

Seasonal allergic rhinitis (SAR) is primarily caused by pollen allergens in the spring or autumn season. The onset of SAR can induce nasal symptoms, sleep disorders, and negative mood. Anemophilous pollen is the major allergen that causes SAR. The spread of pollen tends to peak during the months of March and April in spring and from August to September in autumn $(1,2)$. Pollen concentration is firstly dictated by the existence of anemophilous pollen taxa that cause allergic reactions in an area of interest, and then by meteorological and geographical factors. The persistence of high pollen concentrations, widely believed to be driven 
by global warming and increased atmospheric $\mathrm{CO}_{2}$ levels, represents one of the main causes of the recently increased incidence of allergic rhinitis (AR) (3).

The types of pollen found in Northern China generally come from specific aeroallergens, plants of the genera Populus, Ulmus, Salix, Pinus, and Cupressaceae in the spring, and Artemisia, Chenopodiaceae, and Humulus japonicus in the autumn $(4,5)$. An individual's health and quality of life may be affected by AR, and AR could also decrease learning efficiency and work ability. This combination of negative effects could lead to strain on a person's physiological and mental health, which would ultimately increase the need for clinical treatment of AR in the affected population.

However, the relationship between SAR symptom severity and pollen levels was uncertain. Therefore, we conducted this study to explore the associations between SAR symptom severity and pollen levels in patients with active rhinitis and to investigate the impact on sleep quality and next-day negative mood and/or unethical work behavior. We present the following article in accordance with the STROBE reporting checklist (available at http:// dx.doi.org/10.21037/apm-20-267).

\section{Methods}

\section{Subjects}

From June 1, 2018 to September 30, 2018, patients with SAR at the Beijing Tongren Hospital, Capital Medical University between June 1, 2018 and September 30, 2018 were recruited to the study. Daily pollen concentrations in the Beijing area were recorded during the survey period and released by both the Beijing Meteorological Bureau and Beijing Tongren Hospital. This study was conducted in accordance with the Declaration of Helsinki (as revised in 2013) and was conducted with approval from the Ethics Committee of Beijing Tongren Hospital, Capital Medical University (TRECKY2019-026). All participants signed the informed consent form.

\section{Inclusion and exclusion criteria}

Inclusion criteria: (I) patients who were diagnosed as SAR according to the Allergic Rhinitis and its Impact on Asthma (ARIA) guidelines (6); (II) aged over 18 years old; (III) individuals currently employed with regular working and resting times who did not travel to other geographic areas during the survey period (i.e., September
16 through September 30, 2018); (IV) individuals who presented with sustained disease symptoms for more than one year, with major symptoms that included paroxysmal sneezing, rhinorrhea, nasal obstruction, and nasal itching; (V) individuals for whom a nasal endoscopic examination showed pale coloration and edema of the nasal mucosa, as well as a hypertrophic inferior turbinate in the absence of any signs of anatomical abnormalities, including nasal polyps, neoplasms, or a deviated nasal septum; (VI) individuals with positive reactivity for serum allergenspecific IgE against at least one autumn-prevalent pollen (e.g., mug-wort, ragweed, or Humulus japonicus) with a grade of $\geq 2$ but with negative results for spring pollens and indoor allergens.

Exclusion criteria: (I) patients who had severe infections; (II) patients who had severe liver or kidney dysfunction; (III) patients who were evaluated with abnormal mental state via an online baseline questionnaire before diary survey; (IV) patients who had not signed the informed consent form.

\section{Methodology}

In this study, the experience sampling method (ESM) was adopted in a 2-week diary survey. The ESM is a measurement that is commonly used in organizational behavior research. ESM can observe and collect the information with the aid of auxiliary tools (such as clocks, phone or computer). ESM sometimes called the diary method. Hyper-links were created for all content utilizing the SO JUMP software (Ranxing Information Technology Co., Ltd., Changsha). A group of investigators released an invitation to participate in the study via the WeChat app (Tencent Technology Company Ltd., Shenzhen) prior to commencing the study. The study invitation included a detailed description of the study's aims, content and promised anonymity, and confidentiality to all participants, with the data being used only for scientific studies. Afterwards, the survey was released on the WeChat app and sent to eligible patients.

Patients with SAR who met the research criteria using the diary method and in accordance with the study by Yuan et al. (7) were added to the study administrator's "friends list" in WeChat. Then, participants were asked to complete a baseline questionnaire online, a process that took no more than 15 minutes to complete. The investigators and the administrator of the WeChat group released sub-questionnaires at the same time each day between 
September 16 and September 30, 2018. Participants completed the sub-questionnaires within a specified timeframe (i.e., approximately 5 minutes). Participants were asked to complete the sub-questionnaires twice each day Monday through Friday (due to rest translation, the typical lengths of the first and second weeks were 5 and 6 days, respectively, and the total number of workdays for this 2 -week period was 11 days). The two same-day subquestionnaires were referred to as the "morning workday questionnaire" and the "evening workday questionnaire".

\section{The questionnaires}

The questionnaires were distributed as follows: (I) the morning workday questionnaire was released at 8:00 a.m. on workdays, and participants had to complete the questionnaire before 10:00 a.m. The administrator would send a reminder message to participants who had not completed the questionnaire by 9:00 a.m. (II) The evening workday questionnaire was released at 6:00 p.m. on workdays, and participants had to complete the questionnaire before 9:00 p.m. The administrator would send a reminder message to those participants not completing the questionnaire by 10:00 p.m.

\section{Measurement instruments}

Pollen particles were collected by 13 pollen sampling devices in the Beijing area between September 16, and September 30, 2018 to calculate the average daily pollen concentration, which was described as grains per 1,000 square millimeter, not cubic meter (8).

The severity of nasal symptoms including nasal itching, nasal obstruction, continuous sneezing, and watery rhinorrhea were assessed using a symptom scoring system (score $0-3$ ), i.e., $0=$ no symptoms; $1=$ mild symptoms (signs/ symptoms clearly present, but minimal awareness; easily tolerated); 2 = moderate symptoms (definite awareness of signs/symptoms that is bothersome but tolerable); $3=$ severe symptoms (signs/symptoms that is hard to tolerate; causes interference with activities of daily living and/or sleeping) (9).

The Jenkins Insomnia Scale was used to assess participant insomnia and sleeping status during the previous night. The internal consistency coefficient was 0.82 (10). The Diary Study Mood Scale developed by Bledow et al. (11) in 2011 was used to assess the participants' moods. This approach used six adjectives (depressed, angry, unhappy, frustrated, disappointed, and worried) to indicate possible negative moods that the participants could have felt within several hours before the assessment. The severity of these moods experienced by participants ranged from extremely low [1] to extremely high [5]. The reliability coefficient of the scale was $0.976(12)$.

The six-point unidimensional scale developed by Umphress in 2010 (13) was used to assess unethical work behavior. The scale not only assesses the willingness of participants to commit unethical behaviors, but also assesses the actual unethical behaviors committed by them. The reliability $(\alpha=0.88)$ and validity (including construct validity and discriminant validity) of the scale are both relatively high.

\section{Statistical analysis}

This study used Mplus 7 (Muthén \& Muthén, Los Angeles, CA, USA) for the multilayer path analysis according to the methods reported for multilevel data analysis in previous studies $(14,15)$. We used the software program SPSS 20.0 (SPSS Inc., Chicago, IL, USA) to conduct the statistical analysis. Continuous variables were expressed as mean \pm standard deviation (SD). Discontinuous variables were expressed as a percentage (\%). P value $<0.05$ was considered statistically significant.

\section{Results}

\section{The general characteristics}

In this study, a total of 91 patients with SAR were recruited to the study and completed the baseline questionnaire; 87 of them participated in the survey using the diary method. The questionnaire was considered valid if the participant completed the morning and evening sub-questionnaires between September 16 and September 30, 2018, with less than three missed surveys. Ultimately, 261 data points from 15 participants were excluded because the participants had missed too many surveys. Thus, 672 valid data points from 76 participants were included in the analyses. The mean number of sub-questionnaires completed by each participant was 9.461. The effective recovery rate was $71.828 \%$. Ultimately, valid questionnaires were obtained from 76 participants (including 37 men and 39 women). The mean age of the participants was 34.61 years (Table 1). 
Table 1 Demographic and clinical characteristics of the study population $(\mathrm{N}=76)$

\begin{tabular}{lc}
\hline Characteristic & Mean \pm SD \\
\hline Age (years) & $34.51 \pm 7.80$ \\
Sex (male/female); No. (\%) & $37 / 39(48.68 / 52.32)$ \\
Pollen concentration $^{\mathrm{a}}$ & $68.54 \pm 45.17$ \\
In Pollen & $3.99 \pm 0.75$ \\
Allergen level $^{\mathrm{b}}[1-6]$ & $3.61 \pm 1.27$ \\
With asthma/without asthma & $0.15 \pm 0.36$ \\
Nasal symptoms & \\
Nasal itching & $1.83 \pm 0.79$ \\
Nasal obstruction & $1.95 \pm 0.87$ \\
Continuous sneezing & $1.99 \pm 0.85$ \\
Watery rhinorrhea & $1.95 \pm 0.91$ \\
Insomnia & $2.23 \pm 0.88$ \\
Negative mood & $1.66 \pm 0.86$ \\
Unethical behaviors & $1.40 \pm 0.66$ \\
\hline
\end{tabular}

Data are presented as means and standard deviations, unless otherwise noted. a, pollen concentration is described as particles $/ 1,000 \mathrm{~mm}^{2}$. ', for "allergen level", the numbers 1-6 indicate the relative levels of allergen-specific IgE. SAR, seasonal allergic rhinitis.

\section{Demographic and clinical characteristics of the study population}

Table 2 shows the descriptive statistics for the 672 valid datapoints by sex, age, and pollen concentration. In addition, self-reported rhinitis symptoms provided 672 valid datapoints. The disease course, history of asthma, and serum allergen-specific IgE levels together provided 473 valid data-points. The presence of insomnia had 654 valid datapoints, negative mood had 653 valid data-points, and unethical behaviors had 538 valid data-points.

\section{Association between pollen concentration, and nasal symptoms and insomnia, mood, and unethical work behavior}

The findings showed that, in patients with SAR, men had more severe rhinitis symptoms and negative moods than women. Further, younger participants had greater severities of insomnia and negative mood than older participants, younger participants also displayed more severe rhinitis symptoms. In contrast, the severities of nasal obstruction and sneezing were greater among participants who had experienced longer disease courses.

Furthermore, the multi-level linear regression analysis results showed that sex, age, disease course, history of asthma, and serum allergen specific IgE test results were not significantly associated with the variables examined in the daily questionnaires (Table 3). However, age had a marginally negative effect on negative $\operatorname{mood}(\beta=-0.014$, SE $=0.007, t=-1.851 ; \mathrm{P}=0.064)$. Pollen concentration positively affected only rhinitis symptoms $(\beta=0.004, \mathrm{SE}=0.001$, $t=5.361 ; \mathrm{P}<0.001)$. In contrast, rhinitis symptoms had significant positive effects on night-time insomnia $(\beta=0.220$, $\mathrm{SE}=0.075, t=2.917 ; \mathrm{P}<0.01)$ and on a negative $\operatorname{mood}$ the next day $(\beta=0.105, \mathrm{SE}=0.047, t=2.252, \mathrm{P}<0.05)$. Insomnia also had a positive effect on a negative mood the next day $(\beta=0.086, \mathrm{SE}=0.029, t=2.972 ; \mathrm{P}<0.01)$. A negative mood the next day had a direct positive effect on unethical work behavior $(\beta=0.103, \mathrm{SE}=0.051, t=1.998 ; \mathrm{P}<0.05$; Table 3 and Figures 1,2).

\section{Analysis of indirect effects between pollen concentration, nasal symptoms and insomnia, mood, and unetbical work bebavior}

Table 4 shows the results of the multi-level linear regression. An analysis of indirect effects showed that increased pollen concentration directly affected rhinitis symptoms and thus indirectly affected night-time insomnia (estimate $=0.052$, $\mathrm{SE}=0.018, t=2.837 ; \mathrm{P}<0.01)$ and a negative mood the next day (estimate $=0.023, \mathrm{SE}=0.011, t=2.172 ; \mathrm{P}<0.05)$. Pollen concentration also indirectly affected a negative mood the next day through direct effects on rhinitis symptoms and insomnia (estimate $=0.007, \mathrm{SE}=0.003, t=2.119 ; \mathrm{P}<0.05$ ). In addition, the indirect effect pollen concentration had on unethical work behavior through the onset of rhinitis symptoms, insomnia, and a negative mood the next day is marginally significant (estimate $=0.001, \mathrm{SE}=0.000, t=1.789$; $\mathrm{P}=0.07)$.

Aggravated rhinitis symptoms indirectly affected a negative mood the next day through night-time insomnia (estimate $=0.032, \mathrm{SE}=0.013, t=2.455 ; \mathrm{P}<0.05)$, and the indirect effect on unethical work behavior through nighttime insomnia and a negative mood the next day was marginally significant (estimate $=0.003, \mathrm{SE}=0.002, t=1.849$; $\mathrm{P}=0.06$ ). Night-time insomnia indirectly affected unethical work behaviors through a negative mood the next day (estimate $=0.013, \mathrm{SE}=0.006, t=2.135 ; \mathrm{P}<0.05$ ). 


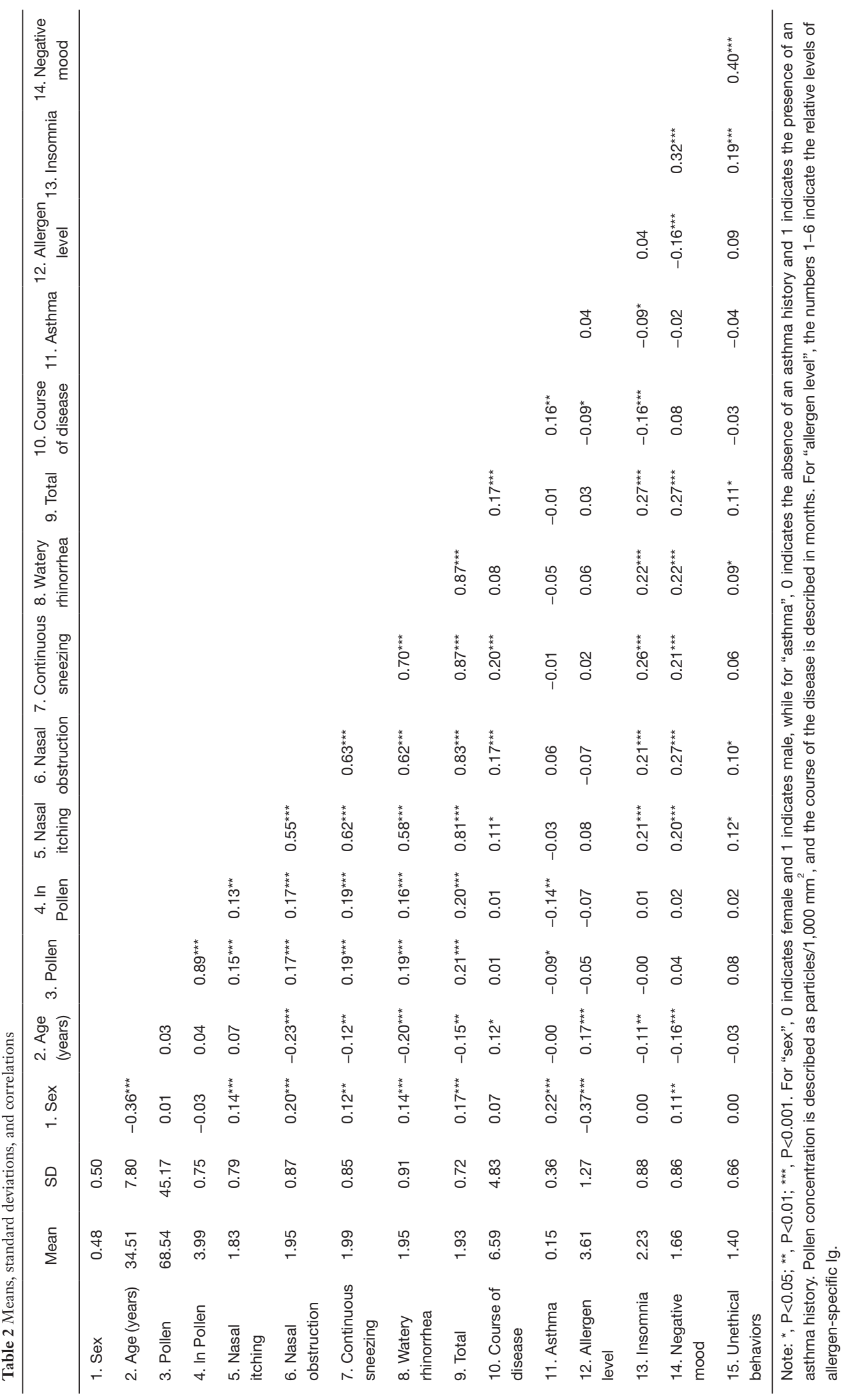


Table 3 Results of the regression analysis

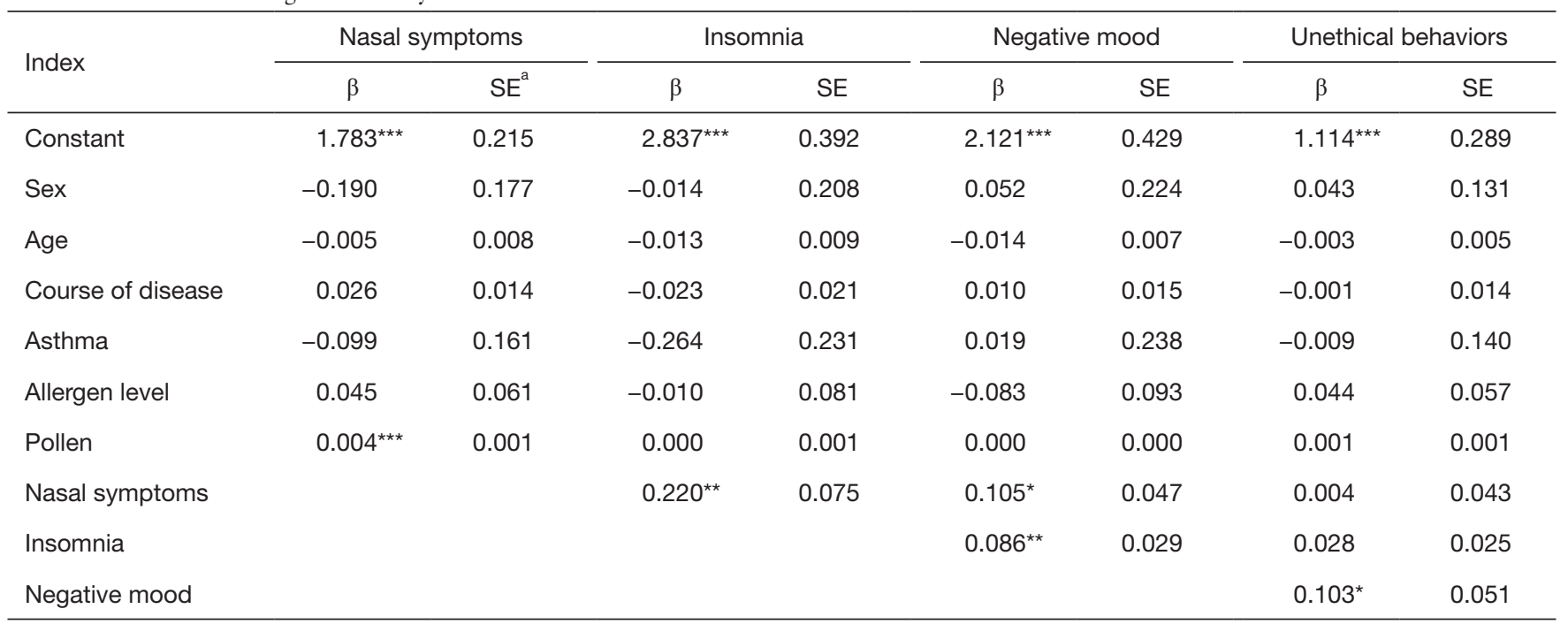

*, $\mathrm{P}<0.05 ;{ }^{* *}, \mathrm{P}<0.01$; ${ }^{* \star *}, \mathrm{P}<0.001 ;{ }^{\text {a }}$, standard error.

$0.004^{\star \star \star}$ $0.220^{\text {** }}$ $0.086^{\star \star}$ $0.103^{*}$

\begin{tabular}{|c|c|c|c|c|c|c|c|c|}
\hline Pollen & $\rightarrow$ & $\begin{array}{c}\text { Nasal } \\
\text { symptoms }\end{array}$ & $\rightarrow$ & Insomnia & $\rightarrow$ & $\begin{array}{l}\text { Negative } \\
\text { mood }\end{array}$ & $\longrightarrow$ & $\begin{array}{l}\text { Unethical } \\
\text { behaviors }\end{array}$ \\
\hline
\end{tabular}

Figure 1 Diagram of the positive effects of pollen concentration on unethical work behaviors. *, $\mathrm{P}<0.05 ;{ }^{* *}, \mathrm{P}<0.01 ;{ }^{* * *}, \mathrm{P}<0.001$.

Average pollen concentration in September 2018

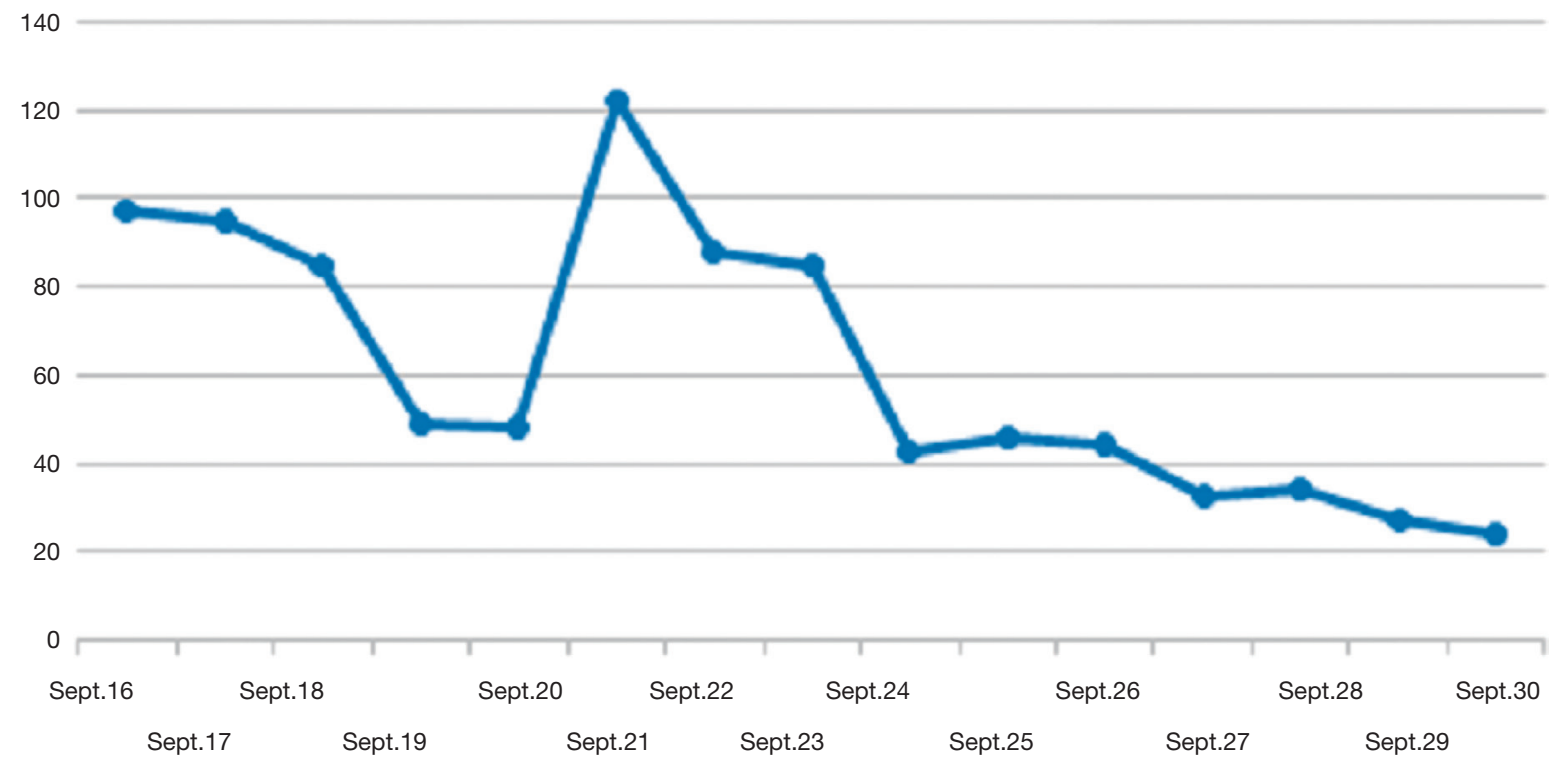

Figure 2 The pollen concentration. 
Table 4 Indirect effects of the study variables

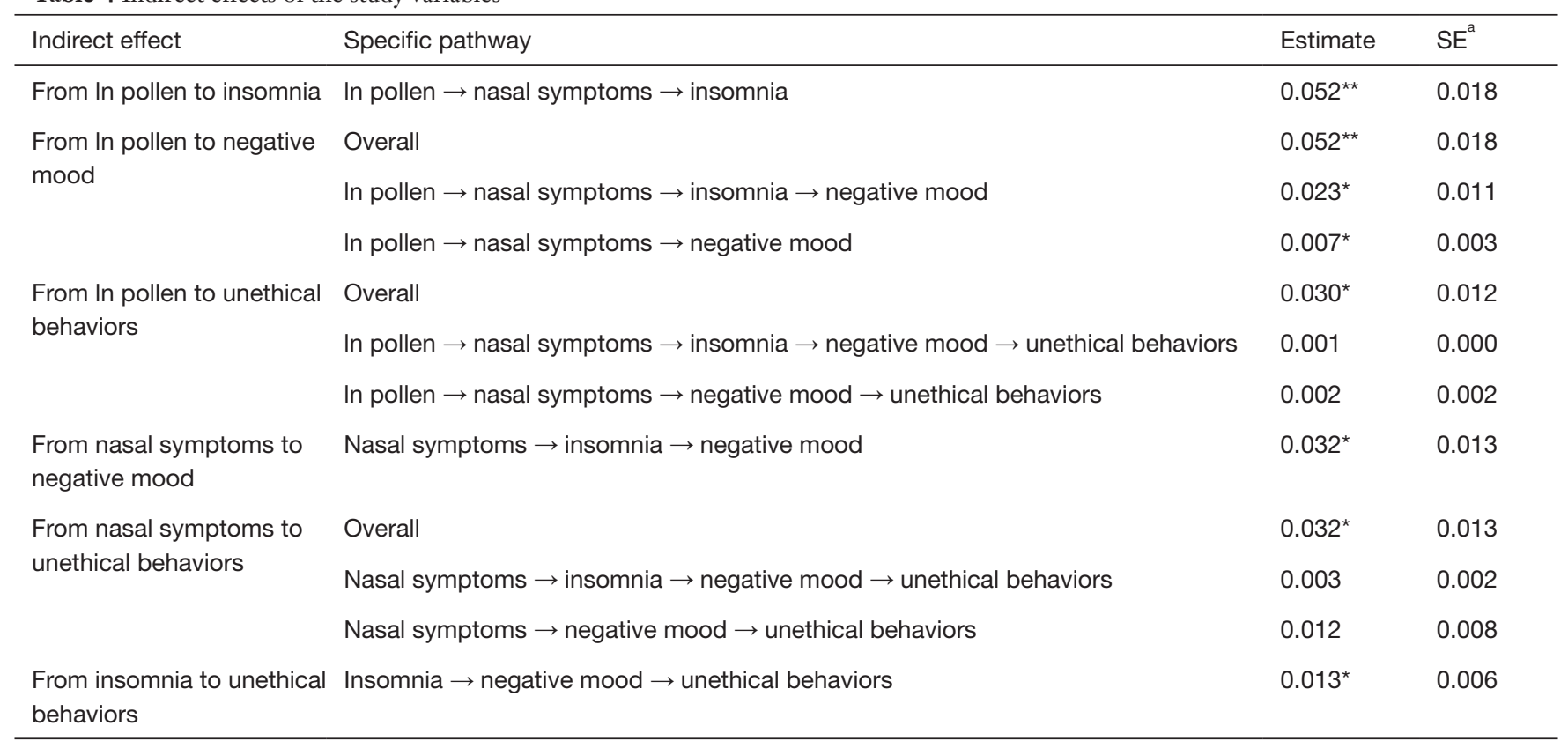

${ }^{+}, \mathrm{P}<0.10 ;{ }^{*}, \mathrm{P}<0.05 ;{ }^{* *}, \mathrm{P}<0.01 ;{ }^{a}$, standard error.

\section{Discussion}

The outcomes of this study presented that pollen concentration had a significant positive effect on rhinitis symptoms. Nasal symptoms had direct, positive effects on night-time insomnia and a negative mood the next day. Insomnia positively affected a negative mood the next day, while negative mood exhibited a direct, positive effect on unethical work behaviors. Furthermore, pollen concentration, nasal symptoms, and insomnia were indirectly but positively associated with unethical work behaviors in patients with SAR.

$\mathrm{AR}$ is a chronic rhinitis commonly encountered in clinical practice. It refers to a condition caused by chronic inflammatory responses of the nasal mucosa induced by IgE-mediated inflammatory factor release and the participation of various immune-competent cells and cytokines after allergen exposure in atopic individuals. $\mathrm{AR}$ is characterized by nasal itching, nasal obstruction, sneezing, and rhinorrhea. Symptoms associated with nasal obstruction could directly affect the severity of participants' state or trait anxiety (16). These symptoms could even cause psychological symptoms, including terrors, insomnia, and depression, which not only increase difficulties in the clinical diagnosis and treatment of the conditions, but might also induce unnecessary conflicts between the physician and the patient $(3,17)$.

SAR, also known as pollinosis, primarily occurs in the spring and autumn seasons. Pollen in the Beijing area of China is mainly derived from plants of the Artemisia, Chenopodiaceae, and Humulus japonicus genera in the autumn, where the pollination period is between August and the end of September. In studies conducted over the course of three consecutive years $(18,19)$, Marshall et al. found that cognitive impairment, distress, and decreased happiness were observed to descend year by year.

Trikojat et al. (20) used the Pittsburgh Sleep Quality Index to evaluate sleep quality in patients with AR during the allergy and non-allergy seasons. Their results showed that sleep quality, sleep efficiency, sleep latency, sleep duration, and usage of hypnotic drugs were significantly different between seasons, suggesting that nasal allergy symptoms could severely disturb both sleep quality and biological rhythm. Approximately $48 \%$ of patients with SAR and $68 \%$ of patients with perennial AR display differential degrees of somnipathy, which has been confirmed as a risk factor for suicide (21).

Mood and emotion are related to feelings. Mood refers to the elongated core emotion of objects without direction, the intensity of which is insufficient to disrupt or interrupt ongoing cognitive thinking. Participants' moods could have 
been affected by various factors, including sleep quality, work resources and events, and interpersonal relationships. The mood of individuals in the workplace has consistently been shown to be associated with work engagement, task performance, organizational citizen behaviors, counterproductive work behavior, and creativity (11,22-24). Individuals' moods before work could affect their emotions as they begin their workday, which in turn could affect how they cognitively process their work. Thus, mood in the workplace has emerged as an essential factor in industrial and organizational psychology studies. Higher levels of positive emotions predict positive work behaviors, whereas higher levels of negative emotions are closely associated with counter-productive work behaviors (25). People who are in bad moods tend to use emotional coping strategies in the workplace, which can affect their interactions with both co-workers and superiors. Negative moods can also distract people from actively engaging in achieving a specific goal, thereby reducing work performance and potentially leading to impulsive or destructive behavior (26).

Ethical behavior is defined as behavior that is both legal and morally acceptable to the larger community in which it occurs, whereas unethical behavior is either illegal or morally unacceptable. Unethical behavior in the workplace refers to behavior that violate the core values of collaboration, law, and ethical standards that serve to promote an effective organization (13). Unethical employee behaviors in the workplace could include the performance of "necessary evils", defiance, and organized misbehavior (27). Unethical behavior is typically associated with negative work performance and has the potential to significantly decrease task performance, leading to psychological and/or physiological damage to other individuals. They also have been found to result in higher workplace accident rates, lower morale and various indicators of poor health (28).

Most studies on the associations between AR and psychological symptoms have been epidemiological. They showed that the most common symptoms among patients with $\mathrm{AR}$ were depression and anxiety. A high prevalence of depressed was observed in AR patients; in addition, patients with depression, anxiety, and AR had higher sleep disturbances than did the general population (29-31). Allergy has even been considered a risk factor for suicide (32). Patients with rhinitis not only experience nasal discomfort, such as nasal itching, nasal obstruction, sneezing, and rhinorrhea, but they may also experience various concomitant symptoms, including fatigue, insomnia, reduced work efficiency, and increased economic burden, which could affect their quality of life $(33,34)$. Untreated $\mathrm{AR}$ is associated with diminished productivity, discomfort and reduced functional ability and even incapacity to work.

In this study, we used the ESM and a novel multi-level dynamic model to examine the effects of various daily variables on next-day work behaviors during the pollen season among patients with SAR who had regular workrest cycles. ESM was also known as the daily diary method, is commonly used in organizational behavior studies. This method uses periodic prompts asking the subject to record momentary assessments of short-term life events, thus permitting the analysis of alterations in patterns of targeted processes and variables in research participants. Using this approach has the potential to effectively decrease the backfill and common method biases. Moreover, recent advances in mobile device technologies, including smart phones, and the development and wider use of apps have also greatly facilitated data capture.

Findings from this study showed that, during the autumn pollen season, nasal symptoms were aggravated in patients with SAR, while sleep quality decreased. In addition, the incidence of insomnia increased, consistent with prior findings (21). We further explored next-day positive and negative moods and work behaviors and identified a positive trend whereby pollen concentration directly or indirectly influenced the other variables. A multi-level linear regression analysis also allowed us to explore indirect effects. The analysis showed that pollen concentration indirectly affected unethical behavior through its direct effects on insomnia and a negative mood the next day. Nasal symptom and insomnia also indirectly affected unethical behavior through their direct effects on a negative mood the next day.

In summary, the symptoms experienced by patients with AR were clearly aggravated during the autumn pollen season, and these symptoms had the potential to affect next-day work behaviors through their direct and indirect effects. Findings from this study provide evidence to support further studies on the associations between work performance and nasal symptoms in the course of a given condition. This study also explored the influence of nasal conditions on work behavior at an individual level. An important theoretical contribution of these findings is to expand the theory that chronic diseases such as AR affect work behaviors by affecting sleep and mood. Our study extends this link to predict and prevent unethical behavior in the workplace. The findings from this study suggest that, with respect to managing staff in a diverse organization 
or enterprise structure, not only is negative mood an important variable, but underlying health conditions should also be causes for concern. Although it is not considered a life-threatening disease, repeated episodes of AR could easily lead to emotional changes, which could in turn result in hostility at the workplace or even engaging in unethical behavior, and finally to increased medical and socioeconomic burdens. Thus, greater attention should be paid to recognizing and treating rhinitis by clinicians, patients with SAR, and authorities in organizational workplace enterprises.

\section{Conclusions}

Nasal symptoms in patients with SAR were aggravated by pollen dispersion that induced a higher incidence of insomnia, which subsequently provoked a negative mood the next day. Therefore, the spillover effects of seasonal pollen included an increased incidence of unethical work behavior.

\section{Acknowledgments}

Funding: This study was partly supported by the National Natural Science Foundation of China (71371179 and 71501177) and the National Key Research and Development Program of China (2016YFC0802600).

\section{Footnote}

Reporting Checklist: The authors have completed the STROBE reporting checklist. Available at http://dx.doi. org/10.21037/apm-20-267

Data Sharing Statement: Available at http://dx.doi. org/10.21037/apm-20-267

Conflicts of Interest: All authors have completed the ICMJE uniform disclosure form (available at http://dx.doi. org/10.21037/apm-20-267). The authors have no conflicts of interest to declare.

Ethical Statement: The authors are accountable for all aspects of the work in ensuring that questions related to the accuracy or integrity of any part of the work are appropriately investigated and resolved. This study was conducted in accordance with the Declaration of Helsinki (as revised in 2013) and was conducted with approval from the Ethics Committee of Beijing Tongren Hospital, Capital Medical University (TRECKY2019-026). All participants signed the informed consent form.

Open Access Statement: This is an Open Access article distributed in accordance with the Creative Commons Attribution-NonCommercial-NoDerivs 4.0 International License (CC BY-NC-ND 4.0), which permits the noncommercial replication and distribution of the article with the strict proviso that no changes or edits are made and the original work is properly cited (including links to both the formal publication through the relevant DOI and the license). See: https://creativecommons.org/licenses/by-nc-nd/4.0/.

\section{References}

1. Pfaar O, Karatzas K, Bastl K, et al. Pollen season is reflected on symptom load for grass and birch polleninduced allergic rhinitis in different geographic areas-An EAACI Task Force Report. Allergy 2020;75:1099-106.

2. Zhang Y, Zhang L. Prevalence of allergic rhinitis in china. Allergy Asthma Immunol Res 2014;6:105-13.

3. Stinson KA, Albertine JM, Hancock LM, et al. Northern ragweed ecotypes flower earlier and longer in response to elevated $\mathrm{CO} 2$ : what are you sneezing at? Oecologia 2016;182:587-94.

4. Cheng Y, Liu H, Wang H, et al. Differentiated climatedriven Holocene biome migration in western and eastern China as mediated by topography. Earth Sci Rev 2018;182:174-85.

5. Huang Y, Zhang Y, Zhang L. Prevalence of allergic and nonallergic rhinitis in a rural area of northern China based on sensitization to specific aeroallergens. Allergy Asthma Clin Immunol 2018;14:77.

6. Bousquet J, Khaltaev N, Cruz AA, et al. Allergic Rhinitis and its Impact on Asthma (ARIA) 2008 update (in collaboration with the World Health Organization, GA(2) LEN and AllerGen). Allergy 2008;63 Suppl 86:8-160.

7. Yuan Z, Barnes CM, Li Y. Bad behavior keeps you up at night: Counterproductive work behaviors and insomnia. J Appl Psychol 2018;103:383-98.

8. Ouyang Y, Li J, Zhang D, et al. A model to predict the incidence of allergic rhinitis based on meteorological factors. Sci Rep 2017;7:10006.

9. Bousquet PJ, Combescure C, Neukirch F, et al. Visual analog scales can assess the severity of rhinitis gradedaccording to aria guidelines. Allergy 2007;62:367-72.

10. Jenkins CD, Jono RT, Stanton, BA. Predicting 
completeness of symptom relief after major heart surgery. Behav Med 1996;22:45-57.

11. Bledow R, Schmitt A, Frese M, et al. The affective shift model of work engagement. J Appl Psychol 2011;96:1246-57.

12. Sonnentag S, Binnewies C, Mojza EJ. "Did you have a nice evening?" A day-level study on recovery experiences, sleep, and affect. J Appl Psychol 2008;93:674-84.

13. Umphress EE, Bingham JB, Mitchell MS. Unethical behavior in the name of the company: The moderating effect of organizational identification and positive reciprocity beliefs on unethical pro-organizational behavior. J Appl Psychol 2010;95:769-80.

14. Robinson SL, Bennett RJ. A typology of deviant workplace behaviors: A multidimensional scaling study. Acad Manag J 1995;38:555-72.

15. Nohe C, Michel A, Sonntag K. Family-work conflict and job performance: A diary study of boundary conditions and mechanisms. J Organ Behav 2014;35:339-57.

16. Xi L, Cao F, Zhang Y, Zhang L. Severity of nasal obstruction can predict the anxiety status of patients with allergic rhinitis but not patients with vasomotor rhinitis. Int Forum Allergy Rhinol 2016;6:1196-203.

17. Cheng L, Chen J, Fu Q, et al. Chinese Society of Allergy Guidelines for Diagnosis and Treatment of Allergic Rhinitis. Allergy Asthma Immunol Res 2018;10:300-53.

18. Marshall PS, O'Hara C, Steinberg P. Effects of seasonal allergic rhinitis on selected cognitive abilities. Ann Allergy Asthma Immunol 2000;84:403-10.

19. Marshall PS, O'Hara C, Steinberg P. Effects of seasonal allergic rhinitis on fatigue levels and mood. Psychosom Med 2002;64:684-91.

20. Trikojat K, Luksch H, Rösen-Wolff A, et al. "Allergic mood" - Depressive and anxiety symptoms in patients with seasonal allergic rhinitis (SAR) and their association to inflammatory, endocrine, and allergic markers. Brain Behav Immun 2017;65:202-9.

21. Bernert RA, Kim JS, Iwata NG, et al. Sleep disturbances as an evidence-based suicide risk factor. Curr Psychiatry Rep 2015;17:554.

22. Shockley KM, Ispas D, Rossi ME, et al. A meta-analytic investigation of the relationship between state affect, discrete emotions, and job performance. Hum Perform 2012;25:377-411.

23. Johnson RE, Tolentino AL, Rodopman OB, et al. We (sometimes) know not how we feel: Predicting job performance with an implicit measure of trait affectivity. Pers Psychol 2010;63:197-219.

24. Baas M, De Dreu CK, Nijstad BA. A meta-analysis of 25 years of mood-creativity research: Hedonic tone, activation, or regulatory focus? Psychol Bull 2008;134:779-806.

25. Miner AG, Glomb, TM. State mood, task performance, and behavior at work: A within-persons approach. Organ Behav Hum Decis Process 2010;112:43-57.

26. Kaplan S, Bradley JC, Luchman JN, et al. On the role of positive and negative affectivity in job performance: a meta-analytic investigation. J Appl Psychol 2009;94:162-76.

27. Kish-Gephart JJ, Harrison DA, Treviño LK. Bad apples, bad cases, and bad barrels: meta-analytic evidence about sources of unethical decisions at work. J Appl Psychol 2010;95:1-31. Erratum in: J Appl Psychol. 2010;95:791.

28. Christopher MB, John S, Megan H. Lack of sleep and unethical conduct. Organ Behav Hum Decis Process 2011;115:169-80

29. Cuffel B, Wamboldt M, Borish L, et al. Economic consequences of comorbid depression, anxiety, andallergic rhinitis. Psychosomatics 1999;40:491-6.

30. Stauder A, Kovacs M. Anxiety symptoms in allergic patients: identification and risk factors. Psychosom Med 2003;65:816-23.

31. Sansone RA, Sansone LA. Allergic rhinitis: relationshipswith anxiety and mood syndromes. Innov ClinNeurosci 2011;8:12-7.

32. Postolache TT, Komarow H, Tonelli LH. Allergy: a risk factor for suicide? Curr Treat Options Neurol 2008;10:363-76.

33. Rondon C, Campo P, Eguiluz-Gracia I, et al. Local allergic rhinitis is an independent rhinitis phenotype: The results of a 10-year follow-up study. Allergy 2018;73:470-8.

34. Wang XY, Ma TT, Wang XY, et al. Prevalence of polleninduced allergic rhinitis with high pollen exposure in grasslands of northern China. Allergy 2018;73:1232-43.
Cite this article as: Xi L, Wang G, Shi B, Li Y, Zhang L. The work behaviors of patients with allergic rhinitis (AR) during the autumn pollen season. Ann Palliat Med 2020;9(5):2776-2785. doi: 10.21037/apm-20-267 